\title{
Study on the Causes and Governance Path of Blood Supply Shortage in China Mainland
}

\author{
Feng Weiping ${ }^{1,}$, Lin Xiaojuan ${ }^{2}$ \\ ${ }^{1}$ Testing Laboratory, Gansu Red Cross Blood Center, Lanzhou, China \\ ${ }^{2}$ Prenatal Diagnosis Center, Gansu Province Maternity and Child-Care Hospital, Lanzhou, China
}

Email address:

fengwp05@163.com (Feng Weiping),410266737@qq.com (Lin Xiaojuan)

${ }^{*}$ Corresponding author

\section{To cite this article:}

Feng Weiping, Lin Xiaojuan. Study on the Causes and Governance Path of Blood Supply Shortage in China Mainland. Science Journal of Public Health. Vol. 4, No. 3, 2016, pp. 229-234. doi: 10.11648/j.sjph.20160403.21

Received: April 14, 2016; Accepted: May 16, 2016; Published: May 19, 2016

\begin{abstract}
In the past five years, the situation of blood supply shortage in China mainland was increasingly grim. The occurrence of blood supply shortage has inevitable objective reasons, but more are subjective reasons that can be avoided originally. The purpose of this paper is that through the analysis of the subjective reasons for the formation of blood supply shortage, to seek the effective way to solve the problem. Analysis shows that the main four causes of blood supply shortage are imperfect incentive mechanism, crisis of confidence, in short supply and the weak foundation. The governance path of blood supply shortages should be multi-governance dominated by the government and involved with multi-organization participation. The government should play a leading role; Blood collection and supply department should improve its service level; Medical institutions should improve the level of scientific and reasonable blood use; Nongovernmental organizations (NGOs) should play their own advantages, to participate in the propaganda and the donation work; The news media should actively participate in social public welfare publicity of blood donation; The general public should trust and support for acquisition and use of blood. For the immediate interests of the public, the relevant departments and personnel should work together and perform its own functions, only in this way the blood supply shortage problem can be effectively alleviated or thoroughly solved.
\end{abstract}

Keywords: Blood Supply Shortage, Causes Analysis, Multi-governance, Multi-organization Participation

\section{Introduction}

On October 1, 1998, China implemented blood donation law, blood donation work into the legalization management track. Blood stations management gradually standardized, blood collection and blood supply service system constantly improve, multi-sectoral collaboration mechanism formation, unpaid blood donation team expands unceasingly, the blood emergency support capability enhances unceasingly, but the problems of shortage of blood supply in recent years also has aroused more attention.

In 2010, Kunming blood center actually stored blood is only $1 / 20$ of the ideal blood storage, inventory only $2200 \mathrm{ml}$ of type O blood. In January 2010 to September, the Beijing collect blood growth was only $2.9 \%$, compared with $10 \%$ increase demand, there was a considerable gap, blood stations in Beijing in October 2010 blood inventory level was less than half of the normal value. Qingdao city street blood donation in 2010 reduced twenty percent compared with the same period in 2009, the number of central Banks has launched three times III level warning blood source security, but also published ten years the first blood II level warning; In early October in Chongqing through the media release, the blood center stock only 1700 bags, the normal inventory should be 4500 bags. In the next two years, the blood shortage situation was not at ease, a report by the end of 2011, according to xinhua, many big cities were still facing the problem of blood.

From 2011, China continues to face significant blood shortages. While there has been some progress in blood collection and supply service in recent years-to the point where the country can basically satisfy its clinical blood needs-a short supply is still a problem in some regions, according to blood supply management experts from the US.

Visible from the above data, although the blood collection 
and blood service system construction in China, and the blood quality and safety management, effective, however, under the situation of rapid development in the medical and health undertakings, the blood work is facing enormous challenges, the blood supplies seriously affect the clinical use of reality $[1,2]$.

The shortage can be attributed to the rapid rise in the demand for clinical blood; a weak donor base for non-remunerated blood donation and the short blood supply in regions with a high concentration of medical establishments [3-5]. Next, we will detailed analyze the various causes of blood shortage, in order to find the methods to solve the problem.

\section{Causes and Analysis}

The occurrence of blood supply shortage has inevitable objective reasons, but more are subjective reasons that can be avoided originally. The subjective causes are varied, but basically have the following kinds [6-8]:

\subsection{Imperfect Incentive Mechanism}

From a deeper level, the causes of blood shortages include incentive mechanism of donating blood is not perfect; the implementation does not reach the designated position.

With the improvement of cultural quality of the citizens in our country, the concept of unpaid blood donation as well as the philosophy for public benefit has more and more accepted by the public, however, at present our country of unpaid blood donation motivation is not strong enough, a lot of policy not in place in time, affecting blood donors blood donation enthusiasm.

"Free" blood preferential policy, for example, according to the regulations of donation: clinical need blood, unpaid blood donors are exempt from the provisions of the preceding paragraph; Unpaid donors spouse and lineal relatives of clinical need blood, can be in accordance with the regulations of the provinces, autonomous regions and municipalities directly under the exemption from or reduction of pay the fees prescribed in the preceding paragraph. However, the situation of the implementation of specific policies is that the blood donors and their families must pay related fees of blood transfusion in the hospital, and then take all kinds of seal to prove (including the using blood time, the amount of blood, the credentials of uinge blood, the doctor signature and the hospital official seal and invoice) of the blood, and then show ID card, certificate, registered permanent residence to the blood stations, so as to take back the corresponding cost of blood. This process is time-consuming, and the service attitude of relevant staff is bad.

As shown in figure 1, there are two kinds of choices for patients with blood shortages, it's not hard to see, the process is complex, and the difficulty of using blood is big. Blood stations did not play a positive role in this process, and it will inevitably affect the public enthusiasm for unpaid blood donation. Using blood how simple, convenient and free, this is the key to implement the incentive mechanism.

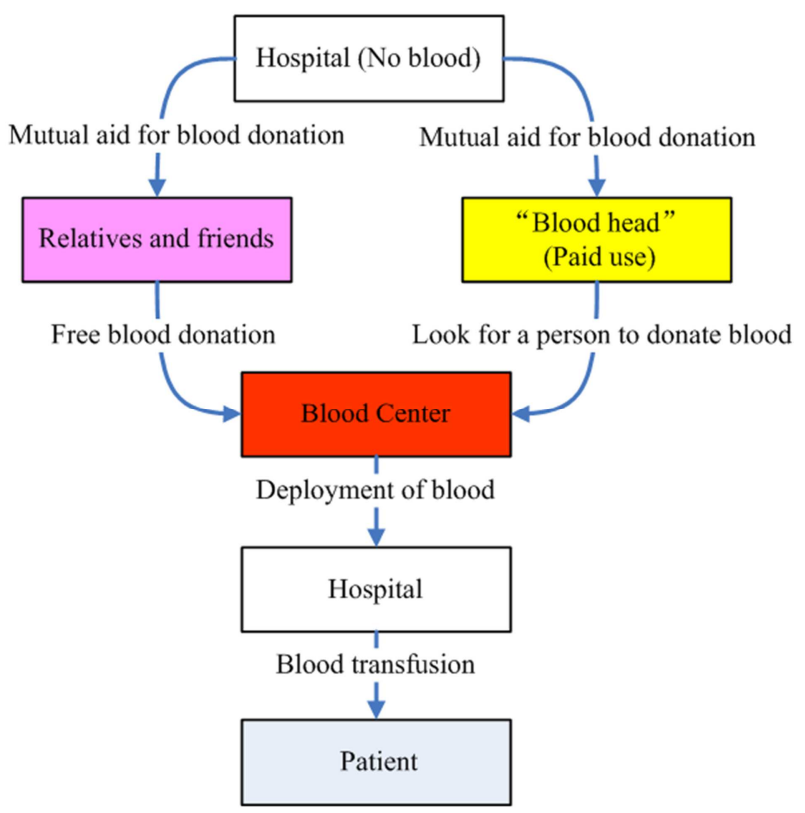

Figure 1. The choice of patients with blood shortages.

\subsection{Crisis of Confidence}

Social trust crisis makes the public distrust in the medical environment. Sina in 2011, 2007 and 2006 unpaid blood donation situation has carried on the online survey of the people, as shown in table 1, a dramatic increase in the proportion of unwilling to donate blood, in just five years, the proportion of unwilling to donate blood dramatically increased five times. In November 2011, Sina netizens did a survey about unpaid blood donation, Participants in the survey generally expressed concerns of blood donation without compensation, in all the survey population, $63.5 \%$ of people said is not willing to donate blood. Table 2 shows why the unwilling to donate blood.

Table 1. No blood donation intention questionnaire.

\begin{tabular}{ll}
\hline Year & Percentage \\
\hline 2006 & $11.0 \%$ \\
2007 & $19.9 \%$ \\
2011 & $63.5 \%$ \\
\hline
\end{tabular}

As you can see in table 2, the public backlash of unpaid blood donation is strong, may be due to the lack of effective health promotion and communication, there are pitfalls for people's understanding of unpaid blood donation policy. About the unpaid blood donation was paid use, although the authorities repeatedly explain this is needed for blood collection, storage, inspection fees, but the public has not seen the release of official data. There are questions for the expensive process of using blood, and suspicious of the whereabouts of the blood, with the influence of network media increasingly prominent in recent years, a lot of the impact of negative news related to blood stations is bad. This distrust is a general lack of trust, namely public doubts about whether certain medical units comply with professional norms. This is suspicious of the government and social public welfare organization if they stick to public welfare. 
Table 2. The results of a survey of not willing to donate blood.

\begin{tabular}{ll}
\hline Reason & Percentage \\
\hline $\begin{array}{l}\text { Unpaid blood donation is paid use } \\
\text { Worry about infectious disease in the process of blood }\end{array}$ & $47.6 \%$ \\
$\begin{array}{l}\text { donation } \\
\text { Preferential policy implementation does not reach the }\end{array}$ & $21.9 \%$ \\
$\begin{array}{l}\text { designated position of unpaid blood donors } \\
\text { Worry about blood donation may do harm to health }\end{array}$ & $15.1 \%$ \\
Other reasons & $7.1 \%$ \\
\hline
\end{tabular}

To a large extent, trust crisis is the result of our country these years not well done the work about the propaganda popularization work of blood donation. On the one hand, it is not enough publicity about the impact of unpaid blood donation only slightly to the body; on the other hand, blood center lacks the introduction for blood stations, collection, storage and use.

Medical cost of using blood became a problem that everyone is interested in. There will be questions, that's "unpaid blood donation, paid use, where is the money then buy blood". In fact, a bag of blood, from the beginning of the unpaid donor's body, through collection, inspection, quality control, storage and transportation process, every step has a cost. As shown in figure 2, each bag $(200 \mathrm{ml})$ blood includes direct costs and indirect costs. Direct costs mainly include detection reagents, blood bags and other medical equipment, disinfection protection, inactivated bacteria such as material cost. For instance, blood center often give unpaid donors souvenirs or milk and other food as encouragement, to carry on some simple tests before blood test, after going through a series of against hepatitis B, hepatitis C, HIV/AIDS, syphilis, transaminase and blood testing, these will have the corresponding costs. The indirect costs include freezing for blood related spending, such as hydropower and blood stations using a variety of testing equipment purchase and maintenance. The parts add up, and the average cost of a bag of blood is about 227 yuan. But the commodity price departments prescribed 200 milliliters per bag of whole blood (including all kinds of blood component) rate is RMB 220, basic equals blood collection, testing and storage cost.

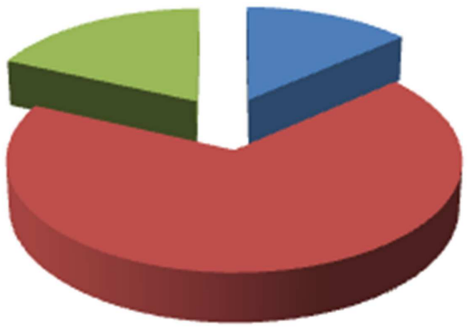

$$
\begin{aligned}
& \text { Blood collected } \\
& \text { material cost }(¥ 30) \\
& \text { All kinds of detection } \\
& \text { reagent cost }(¥ 150) \\
& \text { Propaganda and } \\
& \text { souvenirs cost }(¥ 40)
\end{aligned}
$$

Figure 2. The cost of paid use of blood per $200 \mathrm{ml}$.

\subsection{In Short Supply}

Clinical blood demand rapid growths, the improvement of health care and medical service ability, make the blood supply is facing new pressures and challenges. It shows in figure 3 , in Beijing, for example, in 2010, in pursuance of increment is $2.9 \%$, and a $10 \%$ increase in the demand, this will inevitably further aggravate the blood shortages. The ministry of health website related statistics show that in 2011 the national visit hospital people up to 6.27 billion passengers, number of hospitalization was 152.98 million, increased by 430 million than in 2010 and 11.24 million respectively, compared with 2009, 2010 surgical grew 18.6\%, and the blood collection growth was only $7.7 \%$.

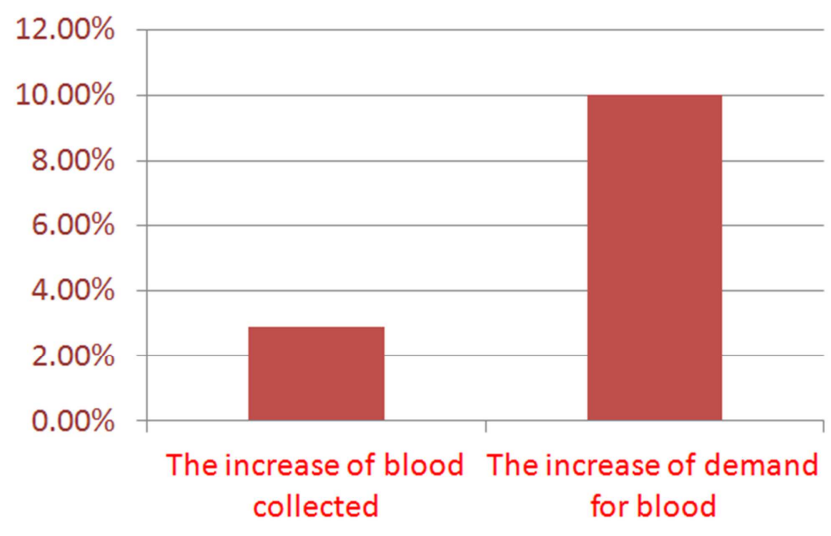

Figure 3. Blood condition growth in Beijing in 2010.

In view of the growing demand, blood donors were lack of team construction. For a long time, a lot of unpaid blood donation of blood stations source mainly comes from the college students and workers, blood donation team structure is simple, when students have a holiday and Spring Festival are prone to seasonal blood shortage.

As shown in figrue 4, statistics show that at present, college students and migrant workers in kunming, the proportion of unpaid blood donation was more than $90 \%$, and the ratio of civil servants to participate in unpaid blood donation account for only $0.92 \%$, the ratio of the medical staff is only $1.2 \%$. Aiming at these problems above, how to improve the enthusiasm, full participation is an effective way to improve the blood supply.

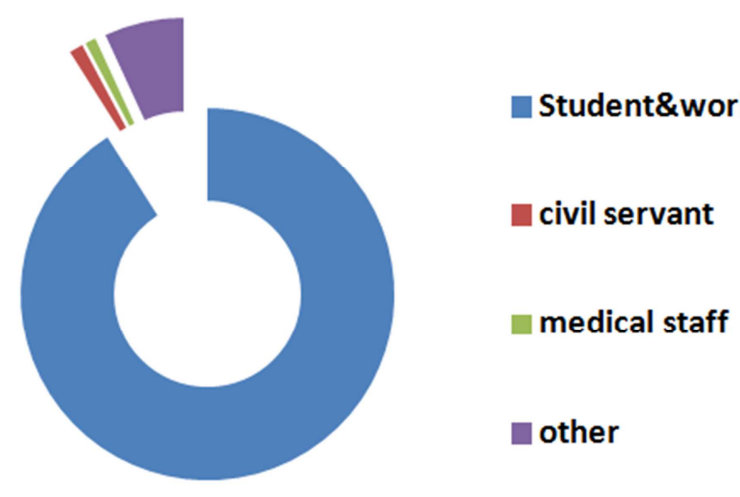

Figure 4. Kunming blood donation population structure in 2010.

Also due to the basic layout of blood stations at all levels concentrate in the medium cities, the coverage of rural areas is limited. Account for important position in China's population structure, the peasant class is in small proportion of blood donation team. This is a weak link in unpaid blood donation work. To effectively increase the blood supply, peasant class must be included in the blood donation team. 


\subsection{The Weak Foundation}

It shws in figure 5, the basis of unpaid blood donation in China is weak, only 9 per thousand population blood donation rate in China mainland. According to the world health organization (WHO) standards, to satisfy their basic needs of clinical blood use, the level of blood donation rate should be $10 \%$ 30\%o.

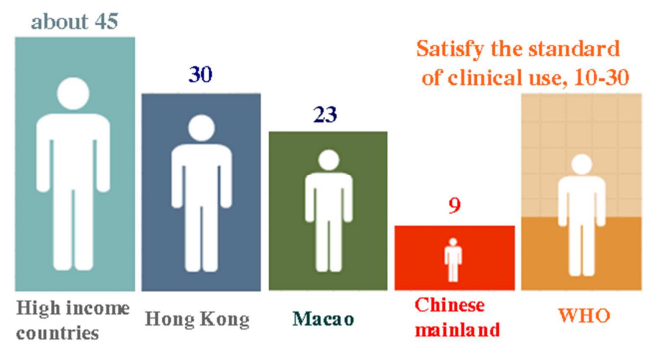

Figure 5. The blood donation number of every 1000 people in 2011.

Calculated at 2011, 12.32 million people to donate blood, about $40000 \sim 50000$ people donate blood every day. Three is a concentration of medical resources in the tight supply situation is not easy to relieve blood shortage, a large number of patients on medical resources rich cities and regions, lead to these places huge demand, obvious gap, blood supply is not easy to relieve tense situation.

Autologous blood transfusion is the best way to use, but is seldom used in the actual operation process. Autologous blood transfusion can not only relieve the strain on clinical use, also can reduce the risk through blood transmitted diseases, prevent allogeneic transfusion hemolysis, fever and allergic reaction, is a very safe way of blood transfusion. Autologous blood transfusion has been carried out abroad for more than 20 years. Then the blood donating law was enacted as early as 12 years ago in China, the country encourages and guides the patient to use own blood storage. However, in the past 12 years, autologous blood transfusion is sluggish. In 2009, the ministry of health again clearly required that the autologous blood transfusion should be actively promoted. The request of autologous blood transfusion proportion rate for level 3 general hospitals should be achieve above $15 \%$. As shown in table 3, in China mainland, the percentage of autologous blood transfusion is only about $1 \%$, and in many Europe countries, autologous blood transfusion surgery is generally introduced, autologous blood transfusion accounted for about $20 \% \sim 40 \%$ of the total use of blood quantity, the United States, Australia is above $60 \%$. In Japan, this proportion is as high as $80 \% \sim 90 \%$.

Thus, autologous blood transfusion such an effective way to solve the problem of blood shortages crisis have not been seriously applied.

Table 3. Autologous blood transfusion percentage.

\begin{tabular}{ll}
\hline Region & Percentage \\
\hline European & $20 \% \sim 40 \%$ \\
Japan & $80 \% \sim 90 \%$ \\
America & $\geq 60 \%$ \\
Australia & $\geq 60 \%$ \\
China & $\approx 1 \%$ \\
\hline
\end{tabular}

\section{Governance Path}

The governance path of blood supply shortages should be multi-governance $[9,10]$, and should be dominated by the government and involved with multi-organization participation.

\subsection{Multi-governance Theory}

The administrative scientist Vincent Ostrom couples introduced "pluralism" into the public affairs management study, and put forward the theory of multi-governance. They think in the public affairs management, whether it is a government monopoly or pure market to provide public services because there is no jump out "the government - the market" either/or management thinking, easy to fall into the "government failure" or "market failure" awkward situation. Them through to the city police, education, transportation and other public affairs operation of a large number of investigation, put forward the effective functioning depends on public affairs by all levels of government and non-governmental organizations, citizens, enterprises and institutions such as multiple subject through dialogue and negotiation way to establish the polycentric governance system. Multi-governance struggle against the centralization and monopoly, it's advocated to form a variety of public affairs management system or organization pattern by the society of multiple independent agents based on certain rules of collective action, by mutual game and debugging, joint cooperation, such as interactive relationship.

Compared to the situation that completely rely on the government or the market management, the multigovernance features both efficiency goals and value orientation of the government at the same time, the private sector, the role of the public and other multiple subject. It also emphasizes the collaborative process and way of democratic, scientific and flexible and the pursuit of win-win results.

As a public welfare undertakings, if unpaid blood donation system run completely depend on the market, due to information asymmetry, externality of blood donation without compensation are likely to produce blood disorder development market chaos, it will inevitably threaten people's life and health. Blood shortages normalized revealed the fact that "failure" of unpaid blood donation system in our country, in fact, this is also a kind of government failure.

Blood shortage is the consequences of path dependence of the government controls, so at this stage, it's time to reshape the policy implementation of the system of unpaid blood donation. Implementation of unpaid blood donation system in China should be a variety of mechanisms and the mode of complex, multi-governance is the necessity of the system of blood donation.

\subsection{Multi-organization Participation}

\subsubsection{The Government}

The government should play a leading role. Government should advance unpaid blood donation work, improve the 
implementation of the related legal policy and regulations. On the legislative ideas, government departments should advocate education organization cadres and the masses to participate in unpaid blood donation. In 2012, the ministry of health had issued a series of policies, and these policies enacted will promote the work of blood donation without compensation, but the specific policy implementation is the key, the government should adhere to the principle of the laws of the real implementation, so as to benefit the public.

The government should also perfect the incentive measures to ensure that unpaid blood donors and their families can enjoy convenient reimbursement service. The government also need to establish a nationwide network of blood bank management system as soon as possible, formulate unified national blood return fee regulations and standards, at the national level, improve the blood supply and regulating mechanism.

The source of financial support for the government financial arrangements need to be able to guarantee blood stations and spending, improve the blood donation environment, increase the investment in blood donation facilities. Blood collecting vehicle need real go into the community, into the campus, into the organs, institutions and enterprises factory, into the busy street.

The government should also to monitor blood services and medical institutions, information disclosure, the reasonable use to strengthen supervision, popularize knowledge of unpaid blood donation, reassure the public, and to guide the public to form correct understanding.

\subsubsection{Blood Center}

Blood collection and supply department should improve its service level. Blood collection and supply department should intensify publicity and recruitment work of blood donation, to improve their ability and level of service. The health ministry has to extend "three goods, one satisfaction" activities to blood collection and supply institutions, namely good service, good quality, good medical ethics, public satisfaction. The blood collection and supply institutions should strive to raise their professional quality and the standard of medical personnel in pursuance of norms, improve the service quality at the same time, to let the blood donors feel warm.

Blood collection and supply institutions should strengthen information disclosure, open the amount of blood storage and use process and using the place to the society, increase social trust and loyalty of blood donation behavior.

Blood collection and supply institutions should continue to increase the propaganda from the depth and breadth of unpaid blood donation. From the fact that blood shortages, effective propaganda of unpaid blood donation in China is still not enough in-depth and comprehensive, blood collection and supply agencies should cooperate with social public and other departments to work together.

\subsubsection{Medical Institutions}

Medical institutions should improve the level of scientific and reasonable blood use. Blood work should be from two aspects of "open source" and "throttling". It is obviously not enough only from the perspective of increasing quantity, must be from the perspective of "throttling", improve the level of scientific and reasonable clinical blood use, effectively use blood resources, ensure the quality of clinical blood use safety and health. In 2009, the relevant person in charge of the ministry of health said that at present our country each year the proportion of unnecessary blood transfusion in clinical use is big. Open source and throttling, reasonable safe blood is the top priority. More than $50 \%$ of the clinical use is unnecessary blood transfusions. This phenomenon has not improved in recent years, on the basis of defining the function to strengthen the construction of organization and with a sound management system as the breakthrough point, through the construction of clinical blood use management organization system and the management of the whole process of clinical blood, use the two main measures to implement the throttle.

\subsubsection{The News Media}

The news media should actively participate in social public welfare publicity of blood donation. The blood donating law stipulates clearly the news media shall carry out social public welfare propaganda to donate blood. The news media plays a very important role in the process of promoting the development of unpaid blood donation in China.

News media should pay attention to the norm of unpaid blood donation campaign. Occasional publicity of blood donation is difficult to achieve sustained, in-depth publicity. News media should strengthen the publicity of the daily news events or blood donation related content, based on the positive propaganda to donate blood to form a good public opinion direction. Only in this way can the public infected in the osmosis and inspiration to love willing to act on the society and others.

News media should pay attention to the way of publicity, and to enhance the influence of the media. The traditional media and network media should mix, expand the influence and coverage of unpaid blood donation propaganda. On the reported methods, typical media should pay attention to the propaganda and the spread of science concept, change traditional didactic, reports about the characters and events to take joint tracking reports, so as to really impress the public.

\subsubsection{Nongovernmental Organizations}

Nongovernmental organizations (NGOs) should play their own advantages, to participate in the propaganda and the donation work. Ngo is a kind of social organization, it's between government and enterprises, for the sake of public welfare undertakings and voluntary, and autonomous operation, also called social intermediate organizations. Ngos are the third option to solve the problem of social and economic, in addition to the government and market. At present our country many place has a lot of unpaid voluntary blood donation of social organizations, such as the red cross volunteer branch, the emergency blood donation volunteers, the hematopoietic stem cell donation volunteers, the young volunteers of the red cross and the red cross volunteer 
community service, etc.

The members of these social organizations include government cadres and workers of state organs, public organizations, enterprises and school teachers and students, personnel of flexible obtain employment, rural farmers, and foreign employees, etc. They fully brought together all kinds of social strength. These ngos should become the main force to promote knowledge and participate in unpaid blood donation work.

\subsubsection{The General Public}

The general public should trust and support for acquisition and use of blood. The authority of the multi-governance mainly comes from the citizen consensus and identity. As the main blood donation, the general public must first break resistance of unpaid blood donation, set up correct concept of blood donation, believe that unpaid blood donation is for everybody, and take an active part in the career of blood donation.

Construction of rural blood collection point is an important approach to improve public participation to donate blood. Related blood management institutions should actively strive for government in funding and support, set up fixed blood collection point in rural, and expand coverage in rural areas, to realize the fundamental change of donors' structure.

Blood donation is a kind of everyone support and mutual aid social public welfare activities. Basically, spontaneous to donate blood rely on public power and the entire social charity enthusiasm and social civilization.

\section{Conclusion}

The occurrence of blood supply shortage has inevitable objective reasons, but more are subjective reasons that can be avoided originally. This paper mainly analyzes the four subjective reasons of the blood supply shortages, namely imperfect incentive mechanism, crisis of confidence, in short supply, and the weak foundation, on this basis, to seek the method to solve the problem of the current increasingly serious blood shortages.

The existence of the blood supply shortage fully exposed the problem of unpaid blood donation work in our country. In order to establish an enduring effect mechanism of unpaid blood donation, there's a lot of work to do. It is necessary to establish the scientific management mode, namely multi-governance, increase the intensity of unpaid blood donation work, and improve the blood donation service specification service behavior, innovation recruiting methods.
Because of unpaid blood donation work involves many aspects, so only the government, the social organizations and the people work together, can truly make better development in the system of blood donation.

\section{Acknowledgements}

We thank Ph. D. Yang Dongya for constructive comments.

\section{References}

[1] Iajya, V., Lacetera, N., Macis, M., Slonim, R., "The effects of information, social and financial incentives on voluntary undirected blood donations: Evidence from a field experiment in Argentina," Social Science \& Medicine, 2013, vol. 98, pp. 214-223.

[2] Andreoni, J., Rao, J. M., "The power of asking: How communication affects selfishness, empathy, and altruism." Journal of Public Economics, 2011, vol. 95, pp. 513-520.

[3] Zhou Jianqiu, "Preliminary study on the causes and its countermeasures of blood supply shortage," China's practical medicine, 2012, no. 2, pp. 264.

[4] Wang Keming, Ma Zujun, "Age-based policy for blood transshipment during blood shortage," Transportation Research Part E-Logistics and Transportation Review, 2015, vol. 80, pp. 166-183.

[5] Yao Jianhua, Yao Jun, "The causes and countermeasures of blood stations in blood supply shortages," China prescription drug, 2014, vol. 12, pp. 98.

[6] Rong Zheng, Han Yuping, Wu Fan, et al., "The blood supply shortage root cause analysis and countermeasures of medical institutions," Journal of Military Surgeon in Southwest China, 2011, vol. 13, no. 6, pp. 1159-1160.

[7] Guo Donghui, Xiang tancheng, Tang Dingjie, et al., "Seasonal and Structural Reasons for Recent Blood Supply Shortage in Jiangsu Province," Clinical blood transfusion and inspection, 2015, vol. 17 , no. 5 , pp. 434-437.

[8] Fan Chinghsiang, Liu, Haoli, Huang Chihying, "Detection of Intracerebral Hemorrhage and Transient Blood-Supply Shortage in Focused-Ultrasound-Induced Blood-Brain Barrier Disruption by Ultrasound Imaging," Ultrasound in Medicine and Biology, 2012, vol. 38, no. 8, pp. 25-28.

[9] Song Li, "How to solve the blood shortage abroad," World Vision, 2010, vol. 22, pp. 56.

[10] Yin Qun, Lian Bin, "Study on path of blood supply shortage governance involved with multi-organization participation," Soft Science of Health, 2013, vol. 27, pp. 1-3. 